\title{
Single nucleotide polymorphisms of microRNA processing genes and outcome of non-Hodgkin's lymphoma
}

This article was published in the following Dove Press journal:

OncoTargets and Therapy

I5 July 2015

Number of times this article has been viewed

\author{
Yuhuan Gao' \\ Lanping Diao' \\ Huan $\mathrm{Li}^{\prime}$ \\ Zhanjun Guo² \\ 'Department of Hematology, \\ 2Department of Gastroenterology and \\ Hepatology, The Fourth Hospital of \\ Hebei Medical University, Shijiazhuang, \\ People's Republic of China
}

Objective: microRNA (miRNA)-related single nucleotide polymorphisms (miR-SNPs) in miRNA-processing machinery genes can affect cancer risk, treatment efficacy, and patients' prognosis by mediating the expression of targeted genes. Five miR-SNPs in miRNA processing machinery genes, including XPO5 (rs11077), RAN (rs14035), TNRC6B (rs9623117), GEMIN3 (rs197412), and GEMIN4 (rs2740348), in 168 non-Hodgkin's lymphoma (NHL) patients were evaluated for their association with the cancer risk and outcomes associated with NHL.

Materials and methods: miR-SNPs were genotyped using polymerase chain reaction-ligase detection reaction. The survival curves were calculated using the Kaplan-Meier method, and comparisons between the curves were made using the log-rank test. Multivariate survival analysis was performed using a Cox proportional hazards model.

Results: Among the five SNPs, only rs197412 located in the coding region of the GEMIN3 gene was identified; it was independently associated with overall survival in NHL patients, as determined by multivariate analysis (relative risk: 1.649; 95\% confidence interval: 1.110-2.449; $P=0.013)$. The prognostic value of this miR-SNP in patient outcomes was also observed in the diffuse large B-cell lymphoma and T-cell lymphoma NHL subtypes.

Conclusion: Our results suggested that the specific genetic variants observed in the miRNA machinery genes may affect NHL survival.

Keywords: miR-SNP, rs197412, GEMIN3, NHL, survival

\section{Introduction}

Human non-Hodgkin's lymphoma (NHL) is the fifth most common cause of cancer worldwide, with diffuse large B-cell lymphoma (DLBCL), T-cell lymphoma (TCL), and follicular lymphoma (FL) as the most common NHL subtypes. ${ }^{1}$ Quite a few patients do not achieve complete remission after conventional chemotherapy for this potentially curable disease. ${ }^{2}$ Clinical factors such as age, stage, number of nodal or extranodal sites, performance status, B symptoms, and certain biochemical measurements have been identified as predictors of NHL outcomes, and these predictive factors were combined as the International Prognostic Index for the prognostic prediction of DLBCL and TCL, and they were subsequently combined as the follicular IPI for FL. ${ }^{1,3-5}$ A number of NHL outcome associated biomarkers have been identified and are associated with NHL outcomes, but few are applied in routine clinical examination. ${ }^{6}$

microRNAs (miRNAs) are RNA molecules with lengths of $\sim 22$ nucleotides, and they act as posttranscriptional regulators of mRNA expression. They are also responsible for regulating the expression of at least $30 \%$ of protein-coding genes. ${ }^{7-9}$ miRNA is implicated in a broad range of biological processes, such as embryonic development, cellular differentiation, proliferation, apoptosis, cancer development,
Correspondence: Zhanjun Guo

Department of Gastroenterology and Hepatology, The Fourth Hospital of

Hebei Medical University, 12 Jiankang

Road, Shijiazhuang 0500II, People's

Republic of China

Tel +86 3II 86095342

Email zjguo5886@aliyun.com 
and insulin secretion. ${ }^{7,8}$ In the miRNA processing, long primary transcripts of miRNAs are processed in the nucleus by the RNase III Drosha, which is transported to the cytoplasm by the nuclear transport factor exportin-5 (XPO5) and Ran-GTPase $(R A N)$. In the cytoplasm, RNase III Dicer and transactivation-responsive RNA-binding protein mediate pre-miRNAs processing to release a 21-bp double-stranded (ds)RNA; the RNA-induced silencing complex, including GEMIN3, GEMIN4, and trinucleotide repeat containing 6B (TNRC6B), will select one strand as the mature miRNA, and they will guide the mature miRNAs to their target mRNA sites. ${ }^{8,10-14}$ miRNA-related single nucleotide polymorphisms (miR-SNPs) - defined as single nucleotide polymorphisms (SNPs) in the miRNA genes, at the miRNA binding site, or in the miRNA processing machinery - can modulate miRNA and targeted genes expression so as to affect cancer risk, treatment efficacy, and patients' prognosis. ${ }^{14-17}$

In the present study, we performed a genotype analysis of five miR-SNPs from the miRNA processing machinery genes, including XPO5 (rs11077), RAN (rs14035), TNRC6B (rs9623117), GEMIN3 (rs197412), and GEMIN4 (rs2740348), which showed an association with cancer risk in a previous study ${ }^{14}$ conducted with 168 NHL patients who received treatment at our hospital. We subsequently evaluated the impact of these miR-SNPs on NHL survival.

\section{Materials and methods}

\section{Tissue specimens and DNA extraction}

Blood samples were collected from 168 NHL patients at the Fourth Hospital of Hebei University who underwent chemotherapy treatment at the Department of Hematology between 2000 and 2007. An NHL diagnosis was made according to the World Health Organization Classification of Tumors. ${ }^{18}$ Blood was also collected from healthy controls. Genomic DNA was extracted immediately with a Wizard Genomic DNA extraction kit (Promega Corporation, Fitchburg, WI, USA). All procedures were supervised and approved by the hospital's Human Tissue Research Committee.

\section{Genotyping of miR-SNPs}

The miR-SNP of the miRNA processing genes including XPO5 (rs11077), RAN (rs14035), TNRC6B (rs9623117), GEMIN3 (rs197412), and GEMIN4 (rs2740348) were genotyped using the ligase detection reaction method, using forward and reverse primers to amplify the DNA fragments that flank the miR-SNPs based on the National Center for Biotechnology Information (NCBI) SNP database (http://www.ncbi.nlm.nih.gov/snp/). Polymerase chain reaction was performed using a polymerase chain reaction Master Mix Kit according to the manufacturer's instructions (Promega Corporation). The ligation was performed using the different probes matched to the miR-SNPs, and the ligated products were separated using the ABI PRISM Genetic Analyzer 3730XL (Thermo Fisher Scientific, Waltham, MA, USA). Polymorphisms were confirmed based on the difference in the length of the ligated products. All primer and probe sequences are listed in Table 1.

\section{Statistical analysis}

The $\chi^{2}$ test was used to analyze dichotomous values, such as the presence or absence of an individual SNP in NHL patients

Table I Five miR-SNPs examined in NHL patients

\begin{tabular}{|c|c|c|c|}
\hline Genes & rs (NCBI) & Primers & Probes \\
\hline \multirow[t]{3}{*}{$X P O 5$} & rsII077 (A/C) & F GAATCTGGTCACCTGATGGGA & SI GTACCTCCAAGGACCAGGGCTGGGA \\
\hline & & R GTGCCTGAGTGGACCTTGAG & S2 TTTGTACCTCCAAGGACCAGGGCTGGGC \\
\hline & & & S3 AGTCTTTAGTGCTAACATCCCCTTT \\
\hline \multirow[t]{3}{*}{ RAN } & rs I $4035(\mathrm{C} / \mathrm{T})$ & F GCACTTGCTCAAAATCTGTGA & SI TTTTAGTAATCATGTTTTAATGTAGAACC \\
\hline & & R TAACAGCAAGAATTCCCAACC & S2 TTTTTTTAGTAATCATGTTTTAATGTAGAACT \\
\hline & & & S3 TCAAACAGGATGGAACATCAGTGGATTT \\
\hline \multirow[t]{3}{*}{ GEMIN4 } & rs2740348 (G/C) & F TTGCCTCTGAGAAGAAGTGG & SI TTTTTTTTGGGAGTAACAGGGCCCTCTTCCGAC \\
\hline & & R GACTCAGGGATGGCTCTGTC & S2 TTTTTTTTTTTTGGGAGTAACAGGGCCCTCTTCCGAG \\
\hline & & & S3 AGCCAGACTTGGTGTTGAGGCTGCTTTTTTT \\
\hline \multirow[t]{3}{*}{ TNRC6B } & rs96231177(C/T) & F TTTCTGTСТССТССТАТССАT & SI TCTCCCTGTTACTCTTAAGTAGTGC \\
\hline & & R CATTAGTTTAGCCAACAAGGT & S2 TTTTCTCCCTGTTACTCTTAAGTAGTGT \\
\hline & & & SЗ CTCCTTTCCCCATCCACCCCATCTC \\
\hline \multirow[t]{3}{*}{ GEMIN3 } & rs I974I2(T/C) & F TAGAGAAACCTGTGGAAATCA & SI TTTTATGGTTTTGTGAGAAATAAAGTTAC \\
\hline & & R GAAGAGGTTCTTGAGCTGTAA & S2 TTTTTTTATGGTTTTGTGAGAAATAAAGTTAT \\
\hline & & & S3 TGAACAGAGAGTCCCTGTGTTGGCATTT \\
\hline
\end{tabular}

Notes: F, represents forward primer for PCR; R, represents reverse primer for PCR; SI and S2, represent probes matched to different alleles of the SNP, S3 represents probes downstream of the SNP.

Abbreviations: miR-SNP, miRNA-related single nucleotide polymorphisms; NHL, non-Hodgkin's lymphoma; NCBI, National Center of Biotechnology Information; XPO5, nuclear transport factor exportin-5PCR; TNRC6B, trinucleotide repeat containing 6B; PCR, polymerase chain reaction; SNP, single nucleotide polymorphism. 
and healthy controls. Pearson's correlation coefficient was used to determine the relationship between clinical characteristics and SNPs. Survival curves were calculated using the Kaplan-Meier method, and comparisons between the curves were made using the log-rank test. Multivariate survival analysis was performed using a Cox proportional hazards model. All of the statistical analyses were performed using the SPSS 18.0 software package (SPSS Inc., Chicago, IL, USA). A $P$-value $<0.05$ was considered statistically significant.

\section{Results}

A total of 177 patients enrolled in this study were reviewed every 3 months for 5 years. Nine patients were lost during follow-up: one in the first year, three in the second year, two in the third year, and three in the fourth year. The remaining 168 patients, including 47 DLBCL, 65 TCL, and seven FL patients, were assessed by univariate and multivariate analyses. At first, the relationship between the data collected during the 5-year follow-up and patients' clinical characteristics was analyzed by log-rank test. The clinical characteristics, including Ann Arbor stage, lactic dehydrogenase (LDH) levels, bone marrow invasion, and the presence of B symptoms, displayed a potential association with the 5-year survival rate. After adjusting the Cox-hazard model using the multivariate analysis findings, Ann Arbor stage, LDH levels, and the presence of B symptoms were identified as the independent predictors for NHL survival (Table 2).

We performed a genotype analysis of these five miR-SNPs of the miRNA processing machinery genes, including XPO5 (rs11077), RAN (rs14035), TNRC6B (rs9623117), GEMIN3 (rs197412), and GEMIN4 (rs2740348) in 168 NHL patients and 80 healthy controls. No statistically significant association $(P>0.05)$ was detected (data not shown) in terms of cancer risk in this case-control study. We subsequently evaluated the association of these genes with overall survival using the Kaplan-Meier methods. Among the five SNPs analyzed, only rs197412 of the GEMIN3 genes had a prognostic impact on overall survival, as determined by the log-rank test analysis

Table 2 Univariate and multivariate analysis of clinical factors associated with NHL survival

\begin{tabular}{|c|c|c|c|c|c|c|}
\hline \multirow[t]{2}{*}{ Factors } & \multirow{2}{*}{$\begin{array}{l}\text { Number of } \\
\text { cases }\end{array}$} & \multirow{2}{*}{$\begin{array}{l}5 \text {-year survival } \\
\text { rate }(\%)\end{array}$} & \multirow{2}{*}{$\frac{\text { Univariate analysis }}{P \text {-value }}$} & \multicolumn{3}{|c|}{ Multivariate analysis } \\
\hline & & & & $\mathbf{R R}$ & $95 \% \mathrm{Cl}$ & $P$-value \\
\hline Age (years) & & & 0.898 & 1.084 & $0.706-1.663$ & 0.712 \\
\hline$\leq 60$ & 125 & 28.8 & & & & \\
\hline$>60$ & 43 & 30.2 & & & & \\
\hline Sex & & & 0.736 & $1.27 \mid$ & $0.849-1.904$ & 0.245 \\
\hline Male & 104 & 30.8 & & & & \\
\hline Female & 64 & 26.6 & & & & \\
\hline Ann Arbor stage & & & 0.000 & 1.721 & $1.063-2.786$ & 0.027 \\
\hline $\mathrm{I} / \mathrm{II}$ & 52 & 46.2 & & & & \\
\hline III/IV & 116 & 21.6 & & & & \\
\hline $\mathrm{LDH}$ & & & 0.000 & 0.509 & $0.334-0.776$ & 0.002 \\
\hline Abnormal & 61 & 11.5 & & & & \\
\hline Normal & 107 & 39.3 & & & & \\
\hline Bone marrow invasion & & & 0.008 & 1.301 & $0.834-2.029$ & 0.246 \\
\hline Normal & 112 & 33.9 & & & & \\
\hline Abnormal & 56 & 19.6 & & & & \\
\hline B symptoms & & & 0.000 & 0.646 & $0.420-0.992$ & 0.046 \\
\hline Yes & 103 & 21.4 & & & & \\
\hline No & 65 & 41.5 & & & & \\
\hline Tumor size & & & 0.114 & 0.956 & $0.620-1.474$ & 0.839 \\
\hline$>5 \mathrm{~cm}$ & 39 & 20.5 & & & & \\
\hline$\leq 5 \mathrm{~cm}$ & 129 & 31.8 & & & & \\
\hline rs1974I2 & & & 0.022 & 1.649 & $1.110-2.449$ & 0.013 \\
\hline $\mathrm{TT}$ & 65 & 38.5 & & & & \\
\hline$C T+C C$ & 103 & 23.3 & & & & \\
\hline Subtypes & & & 0.137 & 0.856 & $0.724-1.012$ & 0.069 \\
\hline DLBCL & 47 & 25.5 & & & & \\
\hline $\mathrm{TCL}$ & 65 & 24.6 & & & & \\
\hline $\mathrm{FL}$ & 7 & 71.4 & & & & \\
\hline Others & 49 & 32.7 & & & & \\
\hline
\end{tabular}

Abbreviations: NHL, non-Hodgkin's lymphoma; LDH, lactic dehydrogenase; DLBCL, diffuse large B-cell lymphoma; TCL, T-cell lymphoma; FL, follicular lymphoma; Cl, confidence interval; RR, relative risk. 


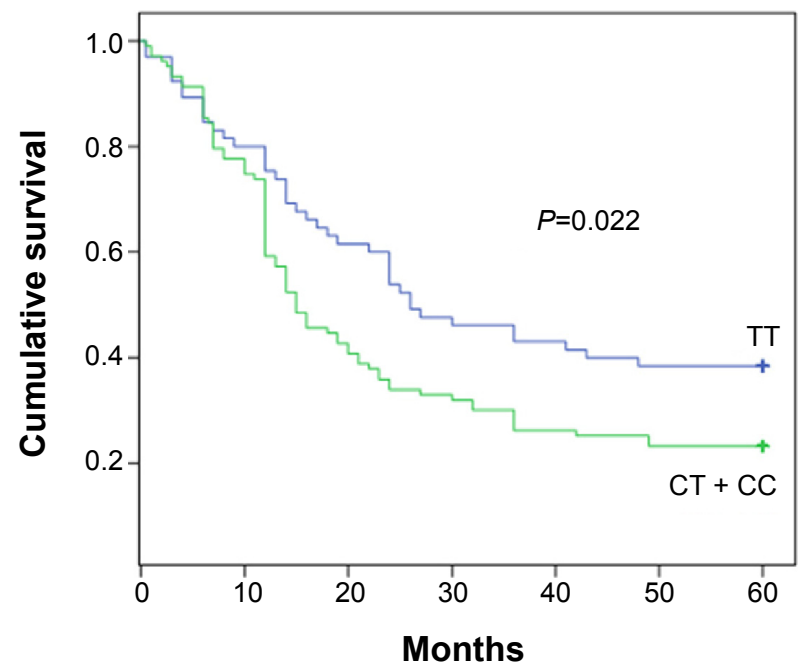

Figure I Genotype of rs 1974 I 2 and its association with total NHL survival. Abbreviation: NHL, non-Hodgkin's lymphoma.

among NHL patients. The 5-year survival rate of CC + CT and TT were $23.3 \%$ and $38.5 \%$, respectively (Table 2 ). The patients with the CT + CC genotype showed a shorter overall survival when compared with that of the TT types (Table 2 and Figure 1). Moreover, the rs197412 SNP was also identified as an independent predictor of NHL outcomes (relative risk:
1.649; 95\% confidence interval [CI]: $1.110-2.449 ; P=0.013$ ) by multivariate analysis with the Cox-hazard model. The correlation analyses of the clinical characteristics and their association with SNPs using Pearson's correlation are listed in Table 2; it was determined that no correlations exist.

The predictive power of rs197412 was assessed in the NHL subtypes by univariate and multivariate analyses. For DLBCL, the 5-year survival rate was $16.7 \%$ in the patients with the $\mathrm{CC}+\mathrm{CT}$ genotype and $41.2 \%$ in those with the TT genotype. The patients with the CC + CT genotype displayed a shorter overall survival, as indicated by the logrank test; this result was marginally statistically significant $(P=0.079$; Table 3 and Figure 2A). After adjusting for Ann Arbor stage, IPI score, LDH levels, and the presence of B symptoms using multivariate analysis, the rs197412 was identified as an independent predictor of DLBCL outcomes; this result was also marginally statistically significant (relative risk: $2.276 ; 95 \% \mathrm{CI}: 0.982-5.273 ; P=0.055)$. For the TCL, the predictive power for survival of this miR-SNP was also validated by univariate $(P=0.005)$ and multivariate analysis (relative risk: 3.106 ; 95\% CI: 1.539-6.267; $P=0.002$ ); this result was statistically significant (Table 4 and Figure 2B).

Table 3 Univariate and multivariate analysis of clinical factors associated with DLBCL survival

\begin{tabular}{|c|c|c|c|c|c|c|}
\hline \multirow[t]{2}{*}{ Factors } & \multirow{2}{*}{$\begin{array}{l}\text { Number of } \\
\text { cases }\end{array}$} & \multirow{2}{*}{$\begin{array}{l}\text { 5-year survival } \\
\text { rate (\%) }\end{array}$} & \multirow{2}{*}{$\frac{\text { Univariate analysis }}{P \text {-value }}$} & \multicolumn{3}{|c|}{ Multivariate analysis } \\
\hline & & & & $\mathbf{R} \mathbf{R}$ & $95 \% \mathrm{Cl}$ & $P$-value \\
\hline Age & & & 0.140 & 1.716 & $0.721-4.087$ & 0.222 \\
\hline$\leq 60$ & 27 & 29.6 & & & & \\
\hline$>60$ & 20 & 20.0 & & & & \\
\hline Sex & & & 0.577 & 1.332 & $0.534-3.325$ & 0.539 \\
\hline Male & 29 & 24.1 & & & & \\
\hline Female & 18 & 27.8 & & & & \\
\hline Ann Arbor stage & & & 0.066 & 1.106 & $0.376-3.254$ & 0.855 \\
\hline $\mathrm{I} / \mathrm{II}$ & 21 & 33.3 & & & & \\
\hline $\mathrm{III} / \mathrm{IV}$ & 26 & 19.2 & & & & \\
\hline LDH & & & 0.037 & 0.759 & $0.207-2.782$ & 0.678 \\
\hline Abnormal & 8 & 12.5 & & & & \\
\hline Normal & 39 & 28.2 & & & & \\
\hline Bone marrow invasion & & & 0.691 & 0.953 & $0.210-4.328$ & 0.950 \\
\hline Normal & 41 & 26.8 & & & & \\
\hline Abnormal & 6 & 16.7 & & & & \\
\hline B symptoms & & & 0.000 & 0.304 & $0.115-0.807$ & 0.017 \\
\hline Yes & 25 & 12.0 & & & & \\
\hline No & 22 & 40.9 & & & & \\
\hline Tumor size & & & 0.583 & 0.733 & $0.299-1.795$ & 0.497 \\
\hline$>5 \mathrm{~cm}$ & 12 & 25.0 & & & & \\
\hline$\leq 5 \mathrm{~cm}$ & 35 & 25.7 & & & & \\
\hline rs 197412 & & & 0.079 & 2.276 & $0.982-5.273$ & 0.055 \\
\hline $\mathrm{TT}$ & 17 & 41.2 & & & & \\
\hline $\mathrm{CT}+\mathrm{CC}$ & 30 & 16.7 & & & & \\
\hline IPI & & & 0.088 & 0.987 & $0.464-2.100$ & 0.973 \\
\hline $0-1$ & 17 & 29.4 & & & & \\
\hline 2 & 20 & 30.0 & & & & \\
\hline $3-5$ & 10 & 10.0 & & & & \\
\hline
\end{tabular}

Abbreviations: DLBCL, diffuse large B-cell lymphoma; Cl, confidence interval; LDH, lactic dehydrogenase; IPI, International Prognostic Index; RR, relative risk. 
A

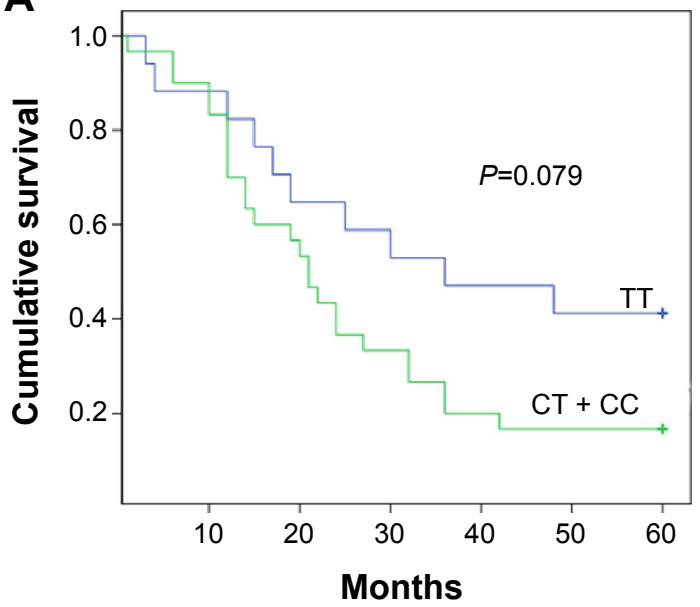

B

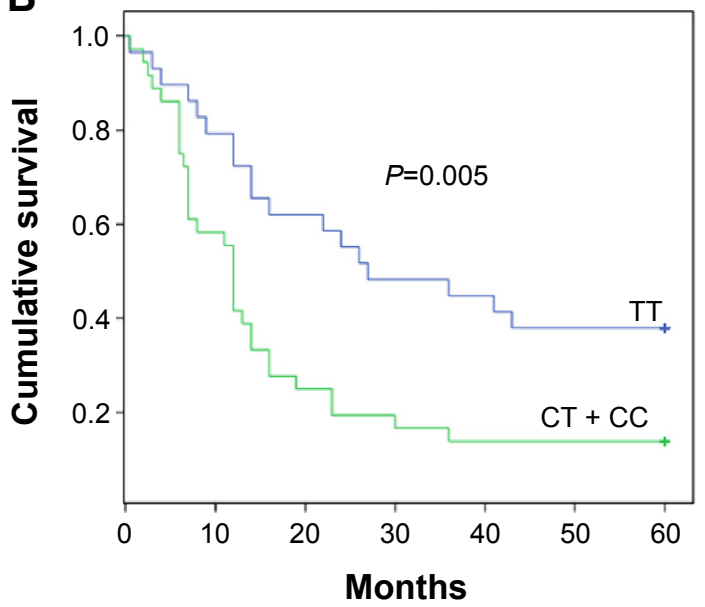

Figure 2 Genotype of rs 197412 in subtypes of $\mathrm{NHL}$ patients.

Notes: (A) Borderline level survival difference for CC + CT and TT genotype of rs 197412 in DLBCL patients. (B) Significant survival difference for CC + CT and TT genotype of rs $1974 / 2$ in TCL patients.

Abbreviations: NHL, non-Hodgkin's lymphoma; DLBCL, diffuse large B-cell lymphoma; TCL, T-cell lymphoma.

\section{Discussion}

In the present study, we reported, for the first time, that miR-SNPs have predictive power on the overall survival of NHL patients. The miR-SNP of rs197412 in the miRNAprocessing machinery genes of GEMIN3 are involved in the prognosis of NHL outcomes. Only a marginal level of significance was observed for the association between miR-SNPs and survival among DLBCL patients, which should be further validated using a larger sample size and in laboratory-based studies.

Table 4 Univariate and multivariate analysis of clinical factors associated with TCL survival

\begin{tabular}{|c|c|c|c|c|c|c|}
\hline \multirow[t]{2}{*}{ Factors } & \multirow{2}{*}{$\begin{array}{l}\text { Number of } \\
\text { cases }\end{array}$} & \multirow{2}{*}{$\begin{array}{l}\text { 5-year survival } \\
\text { rate }(\%)\end{array}$} & \multirow{2}{*}{$\begin{array}{l}\text { Univariate analysis } \\
\text {-value }\end{array}$} & \multicolumn{3}{|c|}{ Multivariate analysis } \\
\hline & & & & $\mathbf{R R}$ & $95 \% \mathrm{Cl}$ & $P$-value \\
\hline Age & & & 0.755 & 1.348 & $0.447-4.065$ & 0.596 \\
\hline$\leq 60$ & 58 & 24.1 & & & & \\
\hline$>60$ & 7 & 28.6 & & & & \\
\hline Sex & & & 0.229 & 1.129 & $0.646-2.452$ & 0.499 \\
\hline Male & 43 & 27.9 & & & & \\
\hline Female & 22 & 18.2 & & & & \\
\hline Stage & & & 0.016 & 1.655 & $0.694-3.945$ & 0.256 \\
\hline $\mathrm{I} / \mathrm{II}$ & 18 & 44.4 & & & & \\
\hline III/IV & 47 & 17.0 & & & & \\
\hline $\mathrm{LDH}$ & & & 0.004 & 1.128 & $0.50 \mathrm{I}-2.540$ & $0.77 \mathrm{I}$ \\
\hline Abnormal & 32 & 12.5 & & & & \\
\hline Normal & 33 & 36.4 & & & & \\
\hline Bone marrow invasion & & & 0.034 & 1.154 & $0.557-2.387$ & 0.700 \\
\hline Normal & 44 & 29.5 & & & & \\
\hline Abnormal & 21 & 14.3 & & & & \\
\hline B symptoms & & & 0.057 & 0.578 & $0.252-1.325$ & 0.195 \\
\hline Yes & 49 & 18.4 & & & & \\
\hline No & 16 & 43.8 & & & & \\
\hline Tumor size & & & 0.546 & 1.429 & $0.664-3.077$ & 0.362 \\
\hline$>5 \mathrm{~cm}$ & 13 & 15.4 & & & & \\
\hline$\leq 5 \mathrm{~cm}$ & 52 & 26.9 & & & & \\
\hline rs1974I2 & & & 0.005 & 3.106 & I.539-6.267 & 0.002 \\
\hline TT & 29 & 37.9 & & & & \\
\hline $\mathrm{CC} / \mathrm{CT}$ & 36 & 13.9 & & & & \\
\hline IPI & & & 0.000 & 2.164 & I.129-4.146 & 0.020 \\
\hline $0-1$ & 20 & 55 & & & & \\
\hline 2 & 31 & 16.1 & & & & \\
\hline $3-5$ & 14 & 0 & & & & \\
\hline
\end{tabular}

Abbreviations: TCL, T-cell lymphoma; $\mathrm{Cl}$, confidence interval; LDH, lactic dehydrogenase; IPI, International Prognostic Index; RR, relative risk. 
GEMIN3 is reportedly implicated in the etiology of spinal muscular atrophy, as it is a core component of the motor neuron complex. ${ }^{19}$ In addition, this protein has been identified in the miRNA ribonucleoprotein particle, which is involved in the processing of miRNA precursors through their interaction with the key components of the RNA-induced silencing complex. ${ }^{19-21}$ For miR-SNP rs197412 located in exon 11 of the GEMIN3 gene, the T to $\mathrm{C}$ transition resulted in Ile and $\mathrm{Thr}$ substitution at the 636 amino acid position of the GEMIN3 protein. This miR-SNP was found to be associated with cancer risk and outcomes in renal cell carcinoma. ${ }^{21,22}$ The underlying mechanism behind how this SNP modifies NHL survival remains unclear; it might affect mRNA stability, which is associated with the altered expression of GEMIN3. The altered GEMIN3 expression may affect the miRNAs as a whole, leading to overall suppression of the miRNA expression profiles, and thus mediating NHL survival. In addition, GEMIN3 can form a complex with $p 53$ and $E B N A 3 C$ to block the DNA binding affinity of $p 53$. In this way, it blocks p53-mediated apoptosis. The C-terminal domain (amino acid 546-825) of GEMIN3 binds to p53 and is responsible for the interaction between GEMIN3 and p53. ${ }^{23}$ The amino acid substitution of this miR-SNP, which is located in the C-terminal of GEMIN3, might alter its binding affinity to p53 and mediate the apoptosis of NHL cells.

Although miR-SNP studies on the miRNA processing machinery genes are in their early stages, our results are encouraging as they indicate that miR-SNPs have an effect on cancer survival. However, the results from this study require validation in other populations and in laboratorybased functional studies. miRNAs have been emphasized as a key factor in patients' susceptibility to therapeutic response in many complex diseases, including cancer. ${ }^{24}$ In conclusion, an miR-SNP in the code region of GEMIN3 was found to be an independent prognostic marker for NHL survival.

\section{Acknowledgment}

This work was supported by Key Basic Research Program of Hebei (14967713D).

\section{Disclosure}

The authors declare that they have no competing interests.

\section{References}

1. Geyer SM, Morton LM, Habermann TM, et al. Smoking, alcohol use, obesity, and overall survival from non-Hodgkin lymphoma: a populationbased study. Cancer. 2010;116:2993-3000.

2. Kube D, Hua TD, von Bonin F, et al. Effect of interleukin-10 gene polymorphisms on clinical outcome of patients with aggressive nonHodgkin's lymphoma: an exploratory study. Clin Cancer Res. 2008;14: 3777-3784.
3. Shipp MA. Prognostic factors in aggressive non-Hodgkin's lymphoma: who has "high-risk" disease? Blood. 1994;83:1165-1173.

4. Solal-Céligny P, Roy P, Colombat P, et al. Follicular lymphoma international prognostic index. Blood. 2004;104:1258-1265.

5. Han X, Kilfoy B, Zheng T, et al. Lymphoma survival patterns by WHO subtype in the United States, 1973-2003. Cancer Causes Control. 2008; 19:841-858.

6. Gascoyne RD. Emerging prognostic factors in diffuse large B cell lymphoma. Curr Opin Oncol. 2004;16:436-441.

7. Bartel DP. MicroRNAs: genomics, biogenesis, mechanism, and function. Cell. 2004;116:281-297.

8. Ambros V. The functions of animal microRNAs. Nature. 2004;431: 350-355.

9. Lewis BP, Burge CB, Bartel DP. Conserved seed pairing, often flanked by adenosines, indicateds that thousands of human genes are microRNA target. Cell. 2005;120:15-20.

10. Cullen BR. Transcription and processing of human microRNA precursors. Mol Cell. 2004;16:861-865.

11. Lee Y, Ahn C, Han J, et al. The nuclear RNase III Drosha initiates microRNA processing. Nature. 2003;425:415-419.

12. Yi R, Qin Y, Macara IG, Cullen BR. Exportin-5 mediates the nuclear export of pre-microRNAs and short hairpin RNAs. Genes Dev. 2003;17: 3011-3016.

13. Chendrimada TP, Gregory RI, Kumaraswamy E, et al. TRBP recruits the Dicer complex to Ago2 for microRNA processing and gene silencing. Nature. 2005;436:740-744.

14. Ryan BM, Robles AI, Harris CC. Genetic variation in microRNA networks: the implications for cancer research. Nat Rev Cancer. 2010;10: 389-402.

15. Guo Z, Wu C, Wang X, Wang C, Zhang R, Shan B. A polymorphism at the miR-502 binding site in the $3^{\prime}$-untranslated region of the histone methyltransferase SET8 is associated with hepatocellular carcinoma outcome. Int J Cancer. 2012;131:1318-1322.

16. Campayo M, Navarro A, Viñolas N, et al. A dual role for KRT81: a miR-SNP associated with recurrence in non-small-cell lung cancer and a novel marker of squamous cell lung carcinoma. PLoS One. 2011;6: e22509.

17. de Larrea CF, Navarro A, Tejero R, et al. Impact of MiRSNPs on survival and progression in patients with multiple myeloma undergoing autologous stem cell transplantation. Clin Cancer Res. 2012;18: 3697-3704.

18. Campo E, Swerdlow SH, Harris NL, Pileri S, Stein H, Jaffe ES. The 2008 WHO classification of lymphoid neoplasms and beyond: evolving concepts and practical applications. Blood. 2011;117:5019-5032.

19. Hutvágner G, Zamore PD. A microRNA in a multiple-turnover RNAi enzyme complex. Science. 2002;297:2056-2060.

20. Dostie J, Mourelatos Z, Yang M, Sharma A, Dreyfuss G. Numerous microRNPs in neuronal cells containing novel microRNAs. RNA. 2003; 9:180-186.

21. Horikawa Y, Wood CG, Yang H, et al. Single nucleotide polymorphisms of microRNA machinery genes modify the risk of renal cell carcinoma. Clin Cancer Res. 2008; 14:7956-7962.

22. Lin J, Horikawa Y, Tamboli P, Clague J, Wood CG, Wu X. Genetic variations in microRNA-related genes are associated with survival and recurrence in patients with renal cell carcinoma. Carcinogenesis. 2010; 31:1805-1812.

23. Cai Q, Guo Y, Xiao B, et al. Epstein-Barr virus nuclear antigen $3 \mathrm{C}$ stabilizes Gemin3 to block p53-mediated apoptosis. PLoS Pathog 2011; 7:e1002418.

24. Iorio MV, Ferracin M, Liu CG. MicroRNA gene expression deregulation in human breast cancer. Cancer Res. 2005;65:7065-7070. 


\section{Publish your work in this journal}

OncoTargets and Therapy is an international, peer-reviewed, open access journal focusing on the pathological basis of all cancers, potential targets for therapy and treatment protocols employed to improve the management of cancer patients. The journal also focuses on the impact of management programs and new therapeutic agents and protocols on
Dovepress

patient perspectives such as quality of life, adherence and satisfaction. The manuscript management system is completely online and includes a very quick and fair peer-review system, which is all easy to use. Visit http://www.dovepress.com/testimonials.php to read real quotes from published authors.

Submit your manuscript here: http://www.dovepress.com/oncotargets-and-therapy-journal 